\title{
Impact of Personality Traits on Compulsive Buying Behavior: Mediating Role of Impulsive Buying
}

\author{
Kiran Shehzadi, Muhammad Ahmad-ur-Rehman, Anam Mehmood Cheema, Alishba Ahkam \\ Department of Management Sciences, National Textile University, Faisalabad, Pakistan \\ Email: kirannouman786@gmail.com
}

How to cite this paper: Shehzadi, K., Ahmad-ur-Rehman, M., Cheema, A.M. and Ahkam, A. (2016) Impact of Personality Traits on Compulsive Buying Behavior: Mediating Role of Impulsive Buying. Journal of Service Science and Management, 9, 416-432.

http://dx.doi.org/10.4236/jssm.2016.95046

Received: July 26, 2016

Accepted: October 15, 2016

Published: October 18, 2016

Copyright $\odot 2016$ by authors and Scientific Research Publishing Inc. This work is licensed under the Creative Commons Attribution International

License (CC BY 4.0).

http://creativecommons.org/licenses/by/4.0/

\begin{abstract}
The prime purpose of this study is to investigate the relationship between personality traits and compulsive buying behavior with mediating role of impulsive buying. By using quantitative research approach, convenience sampling method is selected. Data are collected by using previously established scales. Correlation coefficient and multiple regressions are applied to analyze directions and strength of relationship between variables. According to results agreeableness, neuroticism and openness to experience are three personality traits that are related with compulsive buying with mediating role of impulsive buying. The present study is useful for policy makers, consumers and for society at large. In addition, this investigation provides a starting point for future research with comprehensive theoretical framework.
\end{abstract}

\section{Keywords}

Personality Traits, Impulsive Buying, Compulsive Buying

\section{Introduction}

Not late then past decade, an instant process of change is being observed worldwide in emerging marketplace. There is a huge increase in the number of shopping centers/malls and additional variety in retail shelves making global brands more easily available to consumer than ever. Besides, the purchasing power of consumers in emerging markets has improved because of change in income, information about any product at any place and readily available money. On the other hand, the generous growth of the credit card industry and regression in individual financial responsibility may also contribute to increased purchasing power. These changes might cause an upturn in hedonic shopping value in emerging market consumers, which may result in a 
growth of the frequency rate of impulsive and compulsive buying behavior.

There is a strong public interest in new shopping malls, retail exhibitions, and increasing sales volumes, restaurants, increase in overseas travelling, and prominent international brands opening their outlets in the Pakistan. Additionally, the inspiring performance of fast moving consumer goods (FMCGs) industry also supports this uplifted consumption trend. These facts shows that some people in Pakistan are compulsive buyers, still only few of them know that they are compulsive. Within a high-inflation-low-growth situation, and sluggish employment opportunities in the country, the trend in consumer spending appears strange as real consumption grew by 11.1 percent during Fiscal year 2012, compared to 3.9 percent a year earlier. The ever increasing rate of inflation and price do not seem to have any effect on some buyers as they are addicted to buy and a wide variety of goods attract them which may put them in financial hardships.

By taking into account the generally established significance of personality in determining consumer behavior, this study will examine that personality trait has utmost effect on compulsive buying behavior with mediating effect of impulsive buying. Impulse buying behavior can be defined as an unexpected wish of the buyer for unintended purchase by seeing any product at retail store. Such type of behavior is quite baseless and without any logic. In modern ages, with the progress of fiscal status and selfconscience, impulsive buying has increased (Bashir, 2013) [1].

Compulsive behavior can be defined as doing an act consistently and repetitively without leading it to a desired reward or actual pleasure. The word "compulsive" mentions the feeling of a person that drives him to do an action again and again. Thus compulsive buying is an unusual type of shopping and a psychological disorder.

Extravert persons experience less or minor anxiety because of negative response. Highly extravert persons hold a very optimistic attitude about life. Neuroticism is the state of being neurotic. Neurotic persons tend to be abnormally sensitive and emotionally unstable. Agreeableness personality related trait manifests itself in individual's behavioral features that are supposed as caring, compassionate, obliging, sincere plus sympathetic. Conscientiousness can be defined as wishing to do one's work or duty well and in organized way. Openness element of personality differentiates inventive and ingenious people from usual people.

O'Guinn and Faber (1989) [2] explained compulsive buying in regard to personality traits and impulse buying binges. It was argued that some characteristics in compulsive personalities are similar to each other such as high levels of obsessions and anxiety, high levels of depression, and low self esteem. Compulsive personalities more often involve in harmful behaviors that may be self-destructive even in a way of getting escape from unpleasant feeling. These harmful behaviors may include ritualistic reactions, gambling, frequent impulsive shopping, eating, or alcohol.

Omer (2014) [3] examined the mediating role of impulsive buying between personality traits and compulsive buying. Both compulsive and impulsive buying behaviors are strongly correlated with emotional instability (Neuroticism), among personality traits. 
It means that individuals who experience sadness, irritability, moodiness, anxiety and emotional instability are more disposed to show impulsive leading to compulsive buying behaviors.

Shahjahan (2012) [4] also studied the relationship among impulsive buying behavior, compulsive buying and personality traits. Research demonstrates that those individuals who face emotional instability, anxiety, moodiness, irritability, and sadness are more likely to display impulsive and compulsive buying behaviors. Much compulsive buying is also an outcome of negative feelings and stress. Past research has also found that negative feelings such as anxiety can influence the likelihood of and person to have compulsive buying behaviors (O'Guinn \& Faber, 1989).

According to Donelly (2012) [5] conscientiousness can play a prime role in planning future expenses, it may result in less compulsive buying as well. In previously listed articles it was stated that persons are future oriented that is why they manage their money more, therefore, it is expected that conscientiousness have a novel, negative relationship with compulsive buying, whereas openness to experience is related with compulsive buying because these persons have higher level of impulsiveness.

Another study by Tao Sun (2004) [6] has been conducted to uncover the hierarchical relationship between personality traits, impulsiveness and compulsive buying behavior. In this investigation significant positive relationship was identified between compulsive and impulsiveness. It was proved that emotional instability is directly related with these two purchase related spectrum (impulsive and compulsive), and extraversion is related with impulse buying but not with compulsive buying. Previously established findings are replicated by these findings on compulsive and impulsive buying characteristics. There is strong statistical proves that impulse buying is response of inner traits embedded in personality rather then provoked by external cues. In addition, a significant amount of variance is revealed that compulsive buying can be the result of central and cardinal traits that are impulsive buying and neuroticism.

According to Faber and O'Guinn (1992) [7], lack of impulse control can result in spontaneous or unplanned buying and promote more impulsiveness. This lack of impulse control when comes to a certain point, chronic loss of impulse control accumulated that might develop into compulsive buying. One approach to compulsive buying argue that it is a source of avoiding the frustration of daily life. This argument comes from escape theory by Faber and Vohs, 2004 [8]. Escape theory is a hybrid form of action identification theory and self-awareness theory. According to this theory compulsive buying is the outcome of individual's need to get a way to escape from their self-awareness and from the reality of their lives. This perspective says that compulsive buyers recognize that they are doing an irrational act, but the only solution that they know to make themselves forget the issue is to sink deeper into it. Conflict theory by Bron (1986) [9] can also be employed. In relation to compulsive behavior, conflict theory states that compulsive buyers are a specific segment that has accepted the values of current system without any question. It does not matter for this segment that either their perceived accepted values are in conflict with their own values or not. Because of 
their complete acceptance of the system they are not able to identify it as one of the core reasons of their compulsion. Therefore in an attempt to lessen their suffering they initiate to consume at extraordinary high level. Although the commodities they purchase can provide only a temporary relief, still they continue this activity for short pleasure. This is quite similar to the application of escape theory to compulsive buying (Youn, 2000) [10]. According to social attention theory by Ashton (2002) [11] the core element of extraversion is a tendency to work in such a way that attract, hold, and enjoy social attention. The fundamental quality of social attention is the potential of being rewarded. As a result if a person express positive emotions of intense and eager enjoyment, energy, and excitement, that person is seen favorably by others and gains others' attention. This favorable reaction from others likely encourages extraverts to engage in further extraverted behavior that might leads to impulsion and finally compulsion. According to social attention theory by Ashton (2002) the core element of extraversion is a tendency to work in such a way that attract, hold, and enjoy social attention. The fundamental quality of social attention is the potential of being rewarded. As a result if a person express positive emotions of intense and eager enjoyment, energy, and excitement, that person is seen favorably by others and gains others' attention. This favorable reaction from others likely encourages extraverts to engage in further extraverted behavior that might leads to impulsion and finally compulsion.

Christenson (1994) [12] explained compulsive buying in relation with apparel industry. In this study, twenty-four compulsive buyers were interviewed by using modified structured clinical measures for diagnostic compulsiveness or mental disorder. It was diagnostic that mostly consumers purchase cloths and makeup, which usually went unused by compulsive buyers. In additions, $95.8 \%$ buyers who were compulsive describe their buying in context of impulse control disorder and this sort of behavior is because of their desire of seeking reward.

Other researchers (Schlosser et al., 1994) [13] have open industry specific dimensions of compulsive buying as well. It was proved that majority of compulsive buyers prefer to buy some specific products to which they are habitual like apparel related products. Compulsive buyers show affinity for apparel related product during their compulsive buying episodes and this affinity is quite prominent in the level of involvement in buying process.

Product involvement can be defined as unobservable state that shows the level of emotional attachment, arousal, and interest of a consumer in association with a product. Product involvement of each consumer has some specific continuum that depends on product categories. In general, individuals exhibit different levels of product involvement for different product categories. But for some categories, consumers show all time higher levels of involvement then usual and one of such categories is apparel (Bloch, 1986) [14].

Extraversion is related to impulsive buying behavior.

- There is a relationship between agreeableness and impulse buying behavior.

- Conscientiousness is related to impulse buying behavior. 
- There is a relationship between neuroticism and impulse buying behavior.

- There is a relationship between openness to experience and impulse buying behavior.

- There is a relationship between extraversion and compulsive buying behavior.

- There is a relationship between agreeableness compulsive buying behavior.

- There is a relationship between conscientiousness and compulsive buying behavior.

- There is a relationship between neuroticism and compulsive buying behavior.

- Openness to experience is related to compulsive buying behavior.

- There is a relationship between impulsive buying behavior and compulsive buying behavior.

- There is a mediating effect of impulsive buying behavior between extraversion and compulsive buying behavior.

- There is a mediating effect of impulsive buying behavior between agreeableness compulsive buying behaviors.

- There is a mediating effect of impulsive buying behavior between conscientiousness and compulsive buying behavior.

- There is a mediating effect of impulsive buying behavior between neuroticism and compulsive buying behavior.

- There is a mediating effect of impulsive buying behavior between openness to experience and compulsive buying behavior.

\section{Research Methodology}

First population is determined for this investigation. All male and female customers of well-known apparel select brands who were at least 25 years old or above, having at least 35000 income or above, minimum one year experience with the selected brand and frequency of visit once a month or more, jointly formulated population for this investigation. As Faisalabad is a hub of industrial sector. All outlets of major brands are available here that is why there are opportunities to conduct quality research work focusing apparel industry. Total population Table 1 of all selected brands in Faisalabad is calculated with the help of store manager as 179,200 . This population estimation is subject to off and peak season visits by customer.

Sample size is calculated by using the approach of Israel (1992) [15] at 93\% confidence level and 7\% precision level. Total 300 questionnaires were distributed in order to collect data from apparel customers from which 260 were return back and 60 questionnaires were not valid. Remaining 200 responses are considered for further analysis. Response rate of customers was $86 \%$ as 260 questionnaires out of 300 were return back. Convenience sampling technique is used for this study that is non-probability sampling technique. Convenience sampling is used because customers need to be requested for response immediately after shopping from stated brands. Following previously established scales were used to measure variables.

Personality traits: 44 items scale by John \& Srivastava (1999) [16]. 
Table 1. Apparel brands population in Faisalabad.

\begin{tabular}{|c|c|c|c|c|c|c|}
\hline \multicolumn{7}{|c|}{ Population Size of Different Apparel Brands of Faisalabad } \\
\hline Sr. No. & $\begin{array}{c}\text { Name of } \\
\text { Brand }\end{array}$ & $\begin{array}{c}\text { No. of } \\
\text { Customers per } \\
\text { Day in Peak } \\
\text { Season }\end{array}$ & $\begin{array}{c}\text { Total No. of } \\
\text { Customers In } \\
\text { Peak Season } \\
\text { (90 Days) }\end{array}$ & $\begin{array}{c}\text { No. of } \\
\text { Customers per } \\
\text { Day in off } \\
\text { Season }\end{array}$ & $\begin{array}{c}\text { Total No. of } \\
\text { Customers in } \\
\text { off Season (90 } \\
\text { Days) }\end{array}$ & $\begin{array}{c}\text { Total No. of } \\
\text { Customers } \\
\text { (Off + Peak } \\
\text { Season) }\end{array}$ \\
\hline 1 & Chen One & 150 & 13,500 & $50-60$ & 5400 & 18,900 \\
\hline 2 & $\begin{array}{c}\text { Gul Ahmed } \\
\text { (Ideas) }\end{array}$ & 150 & 13,500 & $40-50$ & 4500 & 18,000 \\
\hline 3 & Ittehad & 200 & 18,000 & $70-80$ & 7200 & 25,200 \\
\hline 4 & $\begin{array}{c}\text { Threads and } \\
\text { Motifs }\end{array}$ & $10-15$ & 1,350 & $10-15$ & 1350 & 2700 \\
\hline 5 & HadiqaKiani & $8-10$ & 900 & $8-10$ & 900 & 1800 \\
\hline 6 & Khaadi & $200+$ & 18,000 & $40-50$ & 4500 & 22,500 \\
\hline 7 & Warda & $20+$ & 1,800 & $20+$ & 1800 & 3600 \\
\hline 8 & Portia & $50+$ & 4,500 & $50+$ & 4500 & 9000 \\
\hline 9 & Nishat & $350-400$ & 36,000 & $50-60$ & 5400 & 41,400 \\
\hline 10 & J. J. & $300+$ & 27,000 & $50-60$ & 5400 & 32,400 \\
\hline \multicolumn{6}{|c|}{ Total No. of Customers In off + Peak Season (Approximately) } & 175,500 \\
\hline
\end{tabular}

Impulsive buying: 9 items scale by Rook and Fisher (1995) [17].

Compulsive buying: 13 item scale by Edward (1963) [18].

According to descriptive statistics 163 respondents were females and remaining were males. 56 respondents were relating to their personal business that is $26.7 \%$ percent of the total sample size.

100 customers out of 200 were doing jobs and make $54.8 \%$ of the entire respondents. 39 respondents responded as others and formulate $18.6 \%$ of all respondents. Age distribution results of 200 respondents indicate that 136 respondents were those who had age in somewhere between 20 to 30 and formulate $70.5 \%$ of entire respondents. 40 respondents were those who belong to second age group (31 - 40) and make 19\% of entire respondents. 20 respondents belong to third age group that is (41 - 50) which is $7.6 \%$ of sample size. 4 respondents belong to last age group (51 - 60) that is 2.4 percent of sample size. Respondents were also probed about their preferred brand. Most of the respondents (68) were customers of chenone and formulate $34 \%$ of entire respondents. Second preferred brand was ideas by gulahmad because 36 respondents prefer gulahmad and make $18 \%$ of entire respondents. Third preferred brand was charcoal. 28 respondents prefer charcoal and make $14 \%$ of total sample size. 8 respondents indicate threads and motifs as their preferred brand that is $4 \%$ of entire sample size. 12 respondents select warda and 12 respondents select nishat and 12 respondents select dinners. All three contribute up to $6 \%$ respectively. Four respondents select J. J that is $2 \%$ of entire respondents. 8 respondents indicate ittehad and it is $4 \%$ and 12 respondents select khaadi, which is $6 \%$ of entire sample size. Experience with the brand frequency response shows that out of 200 respondents, 36 respondents have less then one year expe- 
rience that is $18 \%$ of entire respondents. 124 respondents have experience with the brand for about 1 to five years making $62 \%$ of whole sample size. 32 respondents have experience with the brand for about 6 to 10 years and these respondents are $16 \%$ of total responses. Remaining 8 respondents have experience of 10 years or above for preferred brand and these responses are $4 \%$ of the entire sample. Education of the respondent was also probed in questionnaire. It is found in education frequency results of 200 respondents that $2 \%$ respondents were only matric whereas $4 \%$ respondents were intermediate (Table 2). 50\% respondents have completed bachelor education and 38\% respondents have completed master's degree. $6 \%$ of entire respondents have attained the education of M. Phil. Most of the respondents have attained sixteen-year education that participated in this study. Results of 200 respondents reveal that $54 \%$ respondents fall in first income group that is 35,000 to 45,000 and this is the income range of major portion of respondents. Income of $14 \%$ respondents is between 46,000 to 55,000 and these respondents are 28 out of 200 . Next $14 \%$ respondents earn 56,000 to 65,000 who are exactly 28 respondents again. Higher income range respondents make only $10 \%$ of entire respondents that are exactly 20 respondents. Only $8 \%$ respondents were those who earn 100,000 and above.

All variable are reliable on acceptable continuum as extroversion reliability is 0.62 . Total items for extroversion were 8 from which 2 items, full of energy and talkative, were removed. Reliability for agreeableness is 0.67 . Reliability for conscientiousness is 0.72 , for openness to experience is 0.70 and for neuroticism reliability is 0.78 . Impulsive buying scale is reliable at 0.89 whereas compulsive buying reliability is 0.76 . Correlation and stepwise regression analysis is applied.

\section{Results}

Correlation is applied in order to check relationship among variables that is exhibit in following Table 3.

Correlation examination consequences among extroversion and impulsive buying in Table 3 disclose that extroversion and impulsive buying are not significantly correlated because correlation coefficient value is 0.128 and $\mathrm{p}=0.070$. So $\mathrm{H} 1_{0}$, which states there is no relationship between extroversion and impulsive buying, is accepted.

Correlation analysis also conducted for agreeableness and impulsive buying in Table 3 exposes that agreeableness and impulsive buying are significantly correlated because

Table 2. Education frequency.

\begin{tabular}{cccccc}
\hline & & Frequency & Percent & Valid percent & cumulative percent \\
\hline \multirow{4}{*}{ Valid } & Matric & 4 & 2.0 & 2.0 & 2.0 \\
& Intermediate & 8 & 4.0 & 4.0 & 6.0 \\
& Bachelor & 100 & 50.0 & 50.0 & 56.0 \\
& Master & 76 & 38.0 & 38.0 & 94.0 \\
& M.Phil. & 12 & 6.0 & 6.0 & 100.0 \\
\hline
\end{tabular}


correlation coefficient value is 0.254 and significant because $\mathrm{p}=0.000$.

According to Results of correlation analysis between conscientiousness and impulsive buying behavior, conscientiousness has insignificant correlation with impulsive buying behavior where the value of correlation 0.109 and $\mathrm{p}=0.124$. Hence, $\mathrm{H}_{0}$ which states that there is no relationship between conscientiousness and impulsive buying behavior is accepted. Correlation analysis also conducted between neuroticism and impulsive buying behavior. According to results neuroticism is positively correlated with impulsive buying as the value of correlation coefficient is 0.539 that is significant at $\mathrm{p}$ value $=0.000$.

Table 3. Correlation coefficients.

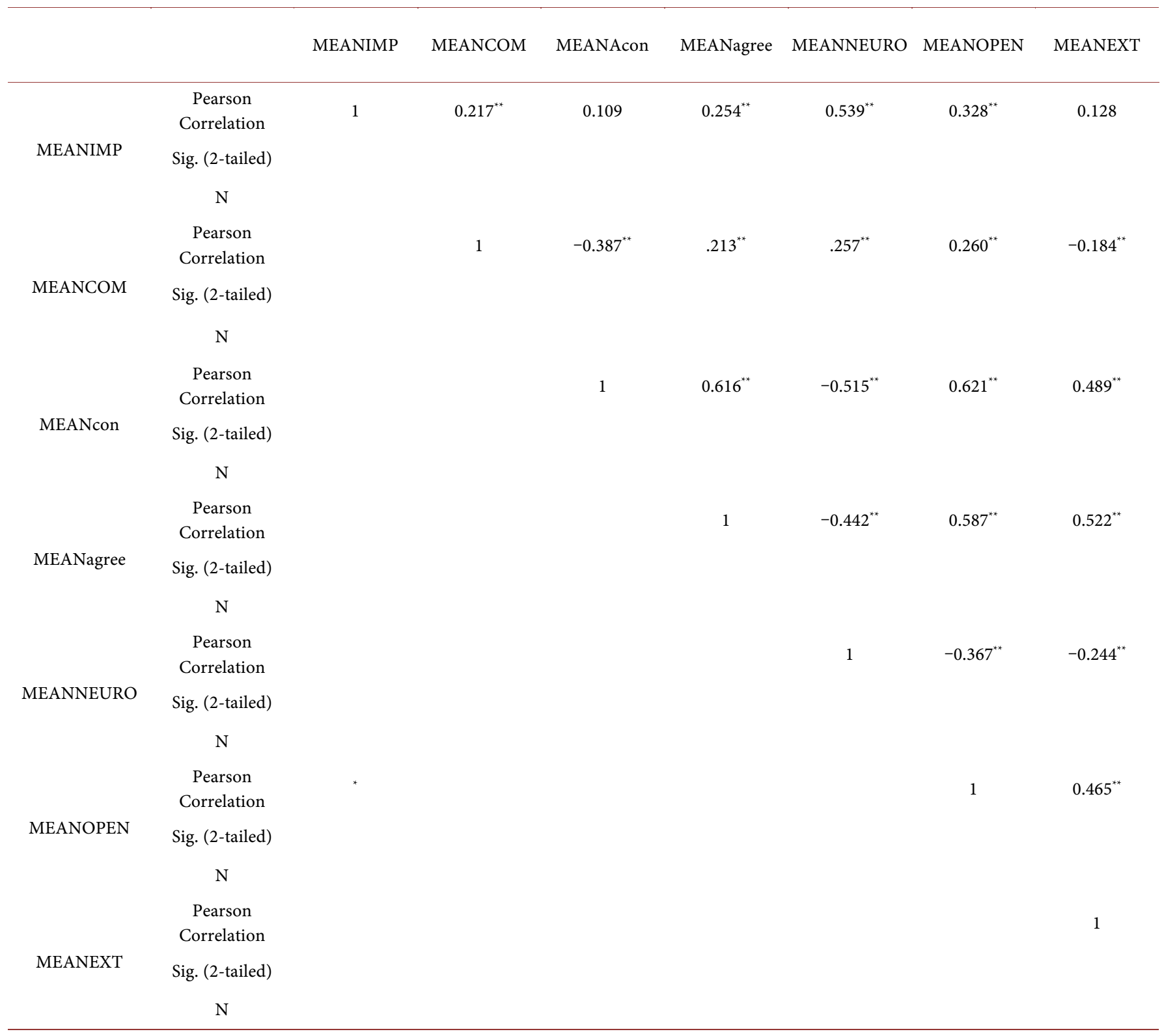

${ }^{* *}$. Correlation is significant at the 0.01 level ( 2 tailed). 
Correlation analysis between openness to experience and impulsive buying behavior shows that openness to experience is significantly correlated with impulsive buying behavior. Correlation coefficient value is 0.328 and $\mathrm{p}=0.000$.

According to results of correlation analysis between impulsive buying behavior and compulsive buying behavior, there is positive correlation between impulsive buying and compulsive buying that is significant at correlation coefficient value $=0.217$ and $\mathrm{p}=$ 0.002 .

Correlation analysis between extraversion and compulsive buying behavior of an individual also conducted. Results describe that extrovert personality trait is in negative correlation with compulsive buying where correlation value is -0.184 and significant at $\mathrm{p}=0.009$.

Correlation analysis was also conducted between agreeableness and compulsive buying behavior of a consumer. According to results agreeableness is negatively but significantly related with compulsive buying behavior. Correlation coefficient value is -0.213 and $\mathrm{p}=0.002$.

Correlation analysis between conscientiousness and compulsive buying behavior shows that there exist negative correlation as correlation coefficient value is -0.387 which is significant because $\mathrm{p}=0.000$.

According to results of correlation analysis between neuroticism and compulsive buying behavior, neuroticism significantly and positively correlate with compulsive buying because correlation coefficient value is 0.257 and $\mathrm{p}=0.000$.

Correlation analysis between openness to experience and compulsive buying behavior demonstrate that openness to experience is significantly and positively correlated with compulsive buying. Correlation coefficient value is 0.260 and $\mathrm{p}=0.000$.

After correlation analysis assumptions of regression are tested. In order to check normality of data skewness and kurtosis has been checked and values falled between -1 and +1 . Normality conditions for openness to experience, neuroticism, conscientiousness, agreeableness, extraversion, impulsive buying behavior and compulsive buying behavior are fulfilled.

In order to check multicollinearity test of tolerance and VIF test are applied. Value of tolerance is 0.999 that is fewer than 1 and value of VIF is 1.00 which is also under control because this value is less than 10 .

Durbin Watson technique is used in order to assess autocorrelation. The values of autocorrelation must be between 1.5 and 2.5 (Durbin, 1970) [19].Data fulfilled all these conditions.

\section{H2. There is a relationship between agreeableness and impulsive buying.}

The relationship between agreeableness and impulsive buying behavior is examined (Table 4). The value of is 0.065 that means 7 percent variation in impulsive buying behavior is because of agreeableness trait of a customer that is significant because $\mathrm{p}=$ 0.000 . If $\mathrm{p}$ value is less than $\alpha=0.05$ than model is considered to be significant. The value of $\beta=0.254$ explain if agreeableness trait of a customer change its value by one unit, then impulsive buying will increase by 0.254 units on average. The value of $\beta$ is signifi- 
cant because $\mathrm{p}$ vale is less then alpha. So $\mathrm{H} 2$ is accepted that relationship exists between agreeableness and impulsive buying behavior of a customer.

\section{H4. There is a relationship between neuroticism and impulsive buying.}

The relationship between neuroticism and impulsive buying behavior was also examined (Table 4). The value of is 0.214 that means about 25 percent change in impulsive buying behavior is because of neuroticism that is significant because the value of $p$ is significant. The value of $\beta$ is 0.330 that means if neuroticism changes its value by one unit then impulsive buying will increase by 0.330 units on average. Thus $\mathrm{H} 4$ which claims that there neuroticism is related with impulsive buying is accepted.

H5. There is a relationship between openness to experience and impulsive buying. Relationship of openness to experience and impulsive buying behavior is examined (Table 4). The value of $=0.107$ that means 10.7 percent variation in impulsive buying behavior is because of openness to experience that is significant because $\mathrm{p}$ value is less then $\alpha \mathrm{p}=0.000$. The value of $\beta$ is 0.328 that means if openness to experience trait change its value by one unit then impulsive buying will increase by .328 units on average. The value of $\beta$ is significant because $\mathrm{p}=0.000$. So $\mathrm{H} 5$ is accepted that claims openness to experience is related with impulsive buying behavior

H6. There is a relationship between impulsive buying and compulsive buying.

The relationship of impulsive buying behavior and compulsive buying behavior is also investigated by controlling demographic variables. According to ANOVA test results all demographic variables are significantly related with compulsive buying behavior. Relationship results among demographic variables and compulsive buying behavior demonstrate that the value of is 0.059 and the value of change is also 0.059 .

The relationship of impulsive buying with compulsive is investigated in step- 2 by controlling the effect of demographic variables (Table 5). The value of is 0.098 that is declined by .059 and reached to the value .039 which is significant because $\beta=0.231$ and $\mathrm{p}=0.005$. It can be articulated that if impulsive buying behavior changed itself by one unit then compulsive buying will increase by .231 units on average. Hence, H6 is accepted that claims the relationship between impulsive buying behavior and compulsive buying behavior.

H7. There is a relationship between extroversion and compulsive buying.

The relationship of extroversion and compulsive buying behavior is also investigated after controlling the effect of demographics (Table 5). The value of is 0.091 that is

Table 4. Regression results.

\begin{tabular}{ccc}
\hline & Impulsive buying & \\
\hline Predictors main effects & $\mathrm{R}^{2}$ & $\beta$ \\
Agreeableness & & \\
Openness to experience & $0.065^{* * *}$ & $0.254^{\star * *}$ \\
Neuroticism & $0.107^{* * *}$ & $0.328^{\star * *}$ \\
\hline
\end{tabular}

${ }^{* * *}$ represents significant relationship. 
Table 5. Regression results with control variables.

\begin{tabular}{ccccc}
\hline & \multicolumn{4}{c}{ Compulsive Buying } \\
\cline { 2 - 5 } & $\beta$ & & Change & $\mathrm{p}$ \\
\hline Step-1 Control Variables (Customer's Demographics) & & 0.059 & 0.059 \\
Step-2 Impulsive buying & 0.231 & 0.098 & 0.039 & 0.005 \\
Extroversion Customer Personality Trait & -0.190 & 0.091 & 0.032 & 0.001 \\
Conscientiousness Customer Personality Trait & -0.364 & 0.182 & 0.123 & 0.000 \\
Agreeableness Customer Personality Trait & 0.210 & 0.101 & 0.043 & 0.000 \\
Neuroticism Customer Personality Trait & 0.281 & 0.134 & 0.076 & 0.000 \\
Openness to Experience Customer Personality Trait & 0.329 & 0.154 & 0.095 & 0.000 \\
\hline
\end{tabular}

reduced by 0.059 and change value is 0.032 that is significant at $\beta=-0.190$ and $\mathrm{p}=$ 0.001 . It means if extroversion personality trait changes its value by one unit compulsive buying will decrease by 0.190 units on average.

H8. There is a relationship between agreeableness and compulsive buying.

The relationship of agreeableness and compulsive buying behavior is also investigated after with controlled effect of demographic variables (Table 5). Results show that the value of is 0.210 after declining by 0.059 the value of change is 0.042 . These results are significant because $\beta=0.210$ and $\mathrm{p}=0.000$. It means if agreeableness trait is changed by one unit compulsive buying will increase by 0.210 units on average. As a result, $\mathrm{H} 8$ is accepted which claims that there is an association between agreeableness and compulsive buying.

H9. There is a relationship between conscientiousness and compulsive buying.

Relationship of conscientiousness and compulsive buying is investigated in step-2 after controlling the effect of demographic variables. Results demonstrate that the value of is 0.182 that is condensed by 0.059 and the value of change is 0.123 . These results are significant at $\beta=-0.364$ and $\mathrm{p}=0.000$. It means if conscientiousness is changed by one unit the compulsive buying will decrease by 0.364 on average. Therefore, H9 is accepted which claims that relationship exist between conscientiousness and compulsive buying behavior.

$\mathrm{H} 10$. There is a relationship between neuroticism and compulsive buying.

In step-2, the association between neuroticism and compulsive buying is investigated by controlling the effect of demographic variables in step-1. Outcomes show that the value of is 0.134 declined by 0.059 , the value of change is 0.075 . These outcomes are significant because $\beta=0.281$ and $\mathrm{p}=0.000$. It means if neuroticism characteristic altered by one unit then compulsive buying will increase by 0.281 units on average. As a result, $\mathrm{H} 10$ is accepted that claims the existence of relationship between neuroticism and compulsive buying behavior.

H11. There is a relationship between openness to experience and compulsive buying.

The relationship of openness to experience and compulsive buying behavior is also investigated by controlling the effect of demographic variables in step-2. According to 
results, the value of is 0.154 and dropped by 0.059 , the value of change is 0.095 . These results are significant because $\beta=0.329$ and $\mathrm{p}=0.000$. It means if openness to experience changed by one unit then compulsive buying behavior is increased by 0.329 . Hence, $\mathrm{H} 11$ is accepted that there exists a relationship between openness to experience and compulsive buying behavior.

H12. Impulsive buying mediates the relationship between extroversion and compulsive buying.

In order to test mediating role of impulsive buying between extroversion and compulsive buying behavior, direct relationships of variable are examined first. Relationship of extroversion and impulsive buying behavior is examined (H1) and found to be insignificant. Relationship of impulsive buying behavior and compulsive buying behavior (H6) is found to be significant. The impact of extraversion personality trait on compulsive buying (H7) is also found to be significant.

According to Baron and Kenny (1986) [20], mediation is possible to investigated only when all three requirements are fulfilled. Hence H12 is rejected that claims the mediating role of impulsive buying between extroversion and compulsive buying behavior.

H13. Impulsive buying mediates the relationship between agreeableness and compulsive buying.

The relationship between agreeableness and impulsive buying behavior (H2) is examined and found to be significant. The relationship between impulsive buying behavior and compulsive buying behavior (H6) is also significant. The impact of agreeableness on compulsive buying behavior (H8) is significant as well. When all the conditions of mediation according to Baron and Kenny (1986) are fulfilled then mediation is investigated. According to results (Table 6), the value of $\beta$ is 0.210 is converted to -0.207 . change value from 0.101 to 0.054 and the value of change 0.043 converted to 0.015 . These results are significant because $\beta=0.207$ and $p=0.100$. So both conditions of mediation are met $\mathrm{H} 13$ is accepted which claims the mediating role of impulsive buying between agreeableness and compulsive buying behavior.

H14. Impulsive buying mediates the relationship between conscientiousness and compulsive buying.

The relationship of conscientiousness with impulsive buying is examined (H3) and found to be insignificant. The relationship of impulsive buying with compulsive buying (H6) is found to be significant. The impact of conscientiousness on compulsive buying is also examined and found to be significant (H9).

When all three conditions of mediation were not fulfilled according to Baron and Kenny (1986) mediation was not investigated. Hence, H14 is rejected which claims that impulsive buying play a mediating role between conscientiousness and compulsive buying behavior.

H15. Impulsive buying mediates the relationship between neuroticism and compulsive buying.

The relationship between neuroticism and impulsive buying behavior is examined (H4) and found to be significant. Impact of impulsive buying behavior and compulsive 
buying behavior is also examined (H6) and found to be significant. The influence of neuroticism on compulsive buying behavior is also significant (H10).

When all the conditions are fulfilled mediation is investigated, where the value of $\beta$ is changed from 0.281 to 0.209 . The value of changed from 0.134 to 0.124 and the value of change lowered from 0.076 to 0.029 . These results are significant because $\beta=0.209$ and $\mathrm{p}=0.060$ (Table 7). Hence H15 which states that impulsive buying behavior mediates the relationship between neuroticism and compulsive buying behavior is accepted.

H16. Impulsive buying mediates the relationship between openness to experience and compulsive buying.

The relationship between openness to experience with impulsive buying behavior is examined (H5) and found to be significant. The relationship between impulsive buying behavior and compulsive buying behavior is also found to be significant (H6). Afterwards, the relationship of openness to experience with compulsive buying behavior (H11) is examined and found to be significant as well.

When all the conditions of mediation are fulfilled then mediation is investigated. According to results the value of $\beta$ is changed from 0.329 to 0.310 (Table 8). The value of changed from 0.154 to 0.059 . The value of change lowered from 0.095 to 0.020 . These results are significant because $\beta=0.310$ and $\mathrm{p}=0.090$. Hence H16 is accepted that states there is mediating role of impulsive buying between openness to experience and compulsive buying behavior.

Table 6. Mediation-1.

\begin{tabular}{|c|c|c|c|c|}
\hline & \multicolumn{4}{|c|}{ Compulsive Buying } \\
\hline & $\beta$ & & Change & $\mathrm{p}$ \\
\hline \multicolumn{5}{|l|}{ Main Effects } \\
\hline Agreeableness Customer Personality Trait & 0.210 & 0.101 & 0.043 & 0.000 \\
\hline \multicolumn{5}{|l|}{ Mediation-1 } \\
\hline Step-1 Control Variables & & 0.059 & 0.059 & \\
\hline Step-2 Impulsive Buying & 0.231 & 0.098 & 0.039 & 0.005 \\
\hline Step-3 Agreeableness Customer Personality Trait & 0.207 & 0.054 & 0.015 & 0.100 \\
\hline
\end{tabular}

Table 7. Mediation 2.

\begin{tabular}{ccccc}
\hline & \multicolumn{4}{c}{ Compulsive Buying } \\
\cline { 2 - 4 } & $\beta$ & & Change & $\mathrm{p}$ \\
\hline Main Effects & & & & \\
Customer Personality Trait & 0.281 & 0.134 & 0.076 & 0.000 \\
Mediation-4 & & & & \\
Neuroticism & & 0.059 & 0.059 & \\
Step-1 Control Variables & & 0.098 & 0.039 & 0.005 \\
Step-2 Impulsive Buying & 0.231 & 0.124 & 0.029 & 0.060 \\
\hline
\end{tabular}




\section{Discussion and Conclusions}

According to results individuals who score higher on agreeableness personality trait, neuroticism trait, and openness to experience trait can be compulsive buyer with existing propensity of impulsivity (Figure 1). These buyers do shopping on impulse and if this impulse control accumulates then it converts into compulsive buying. Such transition in buying behavior is quite difficult to face not only for the buyer but also for the family of buyer. These outcomes are in accordance with Eysenck (1985) [21], Badgaiyan (2014) [22], Donelly (2012), Herabadi (2001) [23], and McCrae \& Costa (2008) [24].

Conscientiousness has insignificant relationship with impulsive buying because these sorts of buyers plan their spending carefully. Conscientious personality trait has negative relationship with compulsive buying because more a person becomes responsible, there are less chances of his compulsive buying. Neurotic personalities are emotionally instable so they purchase on the spur of the moment mostly. They want to become socially acceptable. Basically neuroticism is primary response of stress that is why these buyers purchase without prior planning and in excessive quantity in order to reduce their stress. These outcomes are in harmony with Mueller (2015) [25], Koran (2006) [26], Donelly (2012) and Sun (2004) [6].

Table 8. Mediation-3.

\begin{tabular}{|c|c|c|c|c|}
\hline & \multicolumn{4}{|c|}{ Compulsive Buying } \\
\hline & $\beta$ & & Change & $\mathrm{p}$ \\
\hline \multicolumn{5}{|l|}{ Main Effects } \\
\hline 0penness Customer Personality Trait & 0.329 & 0.154 & 0.095 & 0.000 \\
\hline \multicolumn{5}{|l|}{ Mediation-2 } \\
\hline Step-1 Control Variables & & 0.059 & 0.059 & \\
\hline Step-2 Impulsive Buying & 0.231 & 0.098 & 0.039 & 0.005 \\
\hline Step-3 Openness Customer Personality Trait & 0.310 & 0.059 & 0.020 & 0.090 \\
\hline
\end{tabular}

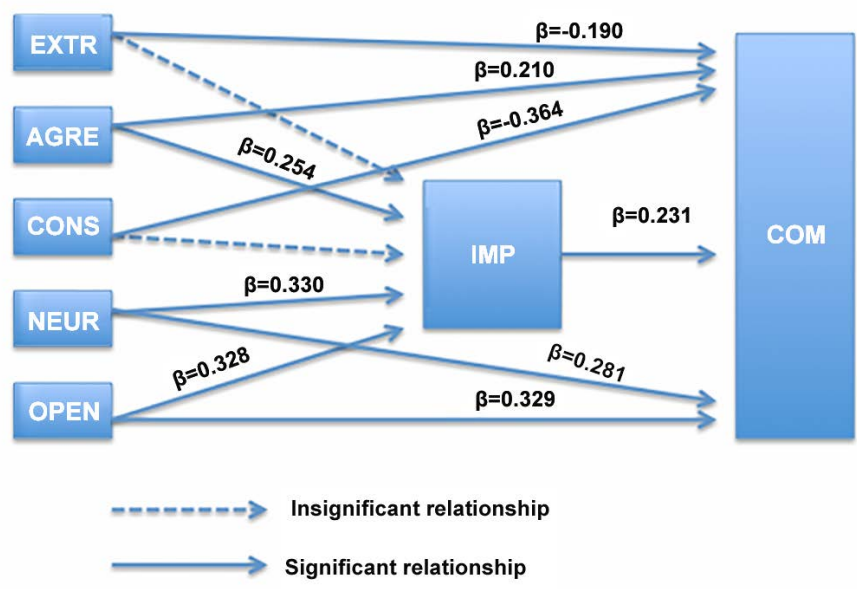

Figure 1. Model. 
There are some limitations of this study as well. First limitation of this study is "convenience-sampling" method. For this investigation data was required from actual customers and this method was convenient to use. As a replacement of this sampling method cluster sampling or quota sampling could be used for data collection. Second, some other sectors like shoes industry, banking industry or car industry may also be considered for investigation other then apparel brands. Larger sample size and inclusion of some moderating variables will also help for better understanding.

In spite limitations, this study contributes in consumer behavior literature and help in understanding the nature of personality traits with resulting buying behavior. In this way, this also studies an addition to the literature of consumer psychology. On the other hand, this investigation is also useful for institutions, policy makers and consumers. Institutes can educate and demotivate this sort of abnormal buying behavior by educating resulting outcomes. Public policy officials and consumer welfare societies can be benefited from this study in order to develop guidelines for marketers and retailers so that they can align their marketing strategies along with some ethical standards. Additionally, suitable social marketing interventions for example counseling and guidance can be formulated in order to tackle increasing ratio of consumer debts because of compulsive buying behavior.

Consumers can have knowledge about this abnormal buying behavior and can access either they are going to lack their impulse control or not.

\section{References}

[1] Bashir, S., Zeeshan, M., Sabbar, S. and Sarki, H. (2013) Impact of Cultural Values and Life Style on Impulse Buying Behavior: A Case Study of Pakistan. International Review of Management and Business Research.

[2] O’Guinn, T.C. and Faber, R.J. (1989) Compulsive Buying: A Phenomenological Exploration. Journal of Consumer Research, 16, 147-157. http://dx.doi.org/10.1086/209204

[3] Omar, N.A., Rahim, R.A., Wel, C.A.C. andAlam, S.S. (2014) Compulsive Buying and Credit Card Misuse among Credit Card Holders: The Roles of Self-Esteem, Materialism, Impulsive Buying and Budget Constraint. Intangible Capital, 10, 52-74.

http://dx.doi.org/10.3926/ic.446

[4] Shahjehan, A., Zeb, F. and Saifullah, K. (2012) The Effect of Personality on Impulsive and Compulsive Buying Behaviors. African Journal of Business Management, 6, 2187-2194. http://dx.doi.org/10.5897/ajbm11.2275

[5] Donelly, G., Iyer, R. and Howell, R.T. (2012) Thebig Five Personality Traits, Material Values, and Financial Well-Being of Self-Described Money Managers. Journal of Economic Psychology, 33, 1129-1142. http://dx.doi.org/10.1016/j.joep.2012.08.001

[6] Sun, T., Wu, G. and Youn, S. (2004) Psychological Antecedents of Impulsive and Compulsive Buying: A Hierarchical Perspective. The Proceedings of the Society for Consumer Psychology 2004 Winter Conference, February 2004, 168-174.

[7] Faber, R.J. and O’Guinn, T.C. (1992) A Clinical Screener for Compulsive Buying. Journal of Consumer Research, 19, 459-469. http://dx.doi.org/10.1086/209315

[8] Faber, R.J. and Vohs, K.D. (2004) To Buy or Not to Buy? Self-Control and Self-Regulatory Failure in Purchase Behavior. 
[9] Baron, R.S. (1986) Distraction-Conflict Theory: Progress and Problems. Advances in Experimental Social Psychology, 19, 1-39. http://dx.doi.org/10.1016/S0065-2601(08)60211-7

[10] Youn, S. and Faber, R.J. (2000) Impulse Buying: Its Relation to Personality Traits and Cues. Advances in Consumer Research, 27, 179-185.

[11] Ashton, M.C., Lee, K. and Paunonen, S.V. (2002) What Is the Central Feature of Extraversion? Social Attention versus Reward Sensitivity. Journal of Personality and Social Psychology, 83, 245-252. http://dx.doi.org/10.1037/0022-3514.83.1.245

[12] Christenson, G.A., Faber, R.J. and Mitchell, J.E. (1994) Compulsive Buying: Descriptive Characteristics and Psychiatric Comorbidity: Dr. Christenson and Colleagues Reply. Compulsive Buying. Marketing Management Journal, 10, 76-79.

[13] Schlosser, S., Black, D.W., Blum, N. and Goldstein, R.B. (1994) The Demography, Phenomenology, and Family History of 22 Persons with Compulsive Hair Pulling. Annals of Clinical Psychiatry, 6, 147-152. http://dx.doi.org/10.3109/10401239409148996

[14] Bloch, P.H. (1986) The Product Enthusiast: Implications for Marketing Strategy. Journal of Consumer Marketing, 3, 51-62. http://dx.doi.org/10.1108/eb008170

[15] Israel, G.D. (1992) Determining Sample Size. University of Florida Cooperative Extension Service, Institute of Food and Agriculture Sciences, EDIS, Florida.

[16] John, O.P. and Srivastava, S. (1999) The Big Five Trait Taxonomy: History, Measurement, and Theoretical Perspectives. In: Pervin, L.A. and John, O.P. Eds., Handbook of Personality: Theory and Research, Vol. 2, Guilford Press, New York, 102-138.

[17] Rook, D.W. and Fisher, R.J. (1995) Normative Influences on Impulsive Buying Behavior. Journal of Consumer Research, 22, 305-313. http://dx.doi.org/10.1086/209452

[18] Edwards, A.L., Walsh, J.A. and Diers, C.J. (1963) The Relationship between Social Desirability and Internal Consistency of Personality Scales. Journal of Applied Psychology, 47, 255-259. http://dx.doi.org/10.1037/h0048882

[19] Durbin, J. (1970) Testing for Serial Correlation in Least-Squares Regression When Some of the Regressors Are Lagged Dependent Variables. Econometrica, 38, 410-421. http://dx.doi.org/10.2307/1909547

[20] Baron, R.M. and Kenny, D.A. (1986) The Moderator-Mediator Variable Distinction in Social Psychological Research: Conceptual, Strategic, and Statistical Considerations. Journal of Personality and Social Psychology, 51, 1173-1182. http://dx.doi.org/10.1037/0022-3514.51.6.1173

[21] Eysenck, S.B., Eysenck, H.J. and Barrett, P. (1985) A Revised Version of the Psychoticism Scale. Personality and Individual Differences, 6, 21-29. http://dx.doi.org/10.1016/0191-8869(85)90026-1

[22] Badgaiyan, A.J. and Verma, A. (2014) Intrinsic Factors Affecting Impulsive Buying Behaviour-Evidence from India. Journal of Retailing and Consumer Services, 21, 537-549. http://dx.doi.org/10.1016/j.jretconser.2014.04.003

[23] Verplanken, B. and Herabadi, A. (2001) Individual Differences in Impulse Buying Tendency: Feeling and No Thinking. European Journal of Personality, 15, S71-S83. http://dx.doi.org/10.1002/per.423

[24] Costa, P.T. and McCrae, R.R. (2008) Chapter 9: The Revised NEO Personality Inventory (NEO-PI-R). In: Boyle, G.J., Matthews, G. and Saklofske, D.H., Eds., The SAGE Handbook of Personality Theory and Assessment. Vol. 2, Personality Measurement and Testing, SAGE Publications, Thousand Oaks, 179-198. http://dx.doi.org/10.4135/9781849200479.n9

[25] Müller, A., Mitchell, J.E. and de Zwaan, M. (2015) Compulsive Buying. The American 
Journal on Addictions, 24, 132-137. http://dx.doi.org/10.1111/ajad.12111

[26] Koran, L., Faber, R., Aboujaoude, E., Large, M. and Serpe, R. (2006) Estimated Prevalence of Compulsive Buying Behavior in the United States. American Journal of Psychiatry, 163, 1806-1812. http://dx.doi.org/10.1176/ajp.2006.163.10.1806

\section{Submit or recommend next manuscript to SCIRP and we will provide best service} for you:

Accepting pre-submission inquiries through Email, Facebook, LinkedIn, Twitter, etc. A wide selection of journals (inclusive of 9 subjects, more than 200 journals)

Providing 24-hour high-quality service

User-friendly online submission system

Fair and swift peer-review system

Efficient typesetting and proofreading procedure

Display of the result of downloads and visits, as well as the number of cited articles

Maximum dissemination of your research work

Submit your manuscript at: http://papersubmission.scirp.org/

Or contact jssm@scirp.org 